\title{
Morpho-based study on urban street spatial configuration: The case of Nanjing city, China
}

\author{
Yihui Yang, Wei You, Yunlong Peng, Wowo Ding* \\ School of Architecture and Urban Planning, Nanjing University, Nanjing, China \\ *(corresponding author) \\ E-mail: tanglian@nju.edu.cn,nju_orange@163.com,dww@nju.edu.cn
}

\begin{abstract}
As the most important part of urban space, street space is often regarded as the urban design object which would be made to reach certain spatial configuration expected by urban designer. As we all know that street space is shaped by the buildings along it, and that the buildings not only belong to different owners but also would be changed through the time. If it is true one might ask how the street space changes and what does this change mean to the urban development. Based upon urban morphological theory this paper investigates the relationships between street spatial configuration and urban development policies, building coding as well as urban activities. Three streets located in the center of Nanjing City with different functions and various land uses along them are selected as the research cases. Though the research this paper will demonstrate that by reading the changes of the street spatial configurations we can understand the social development stages and times, and by evaluating the street spatial configurations through the time we can see how the land policies changed the spaces. The paper suggests that confronting the dynamic phenomenon of the urban street space, urban designer should see urban form as urban morph, which will help designers to make decision more proper and better.
\end{abstract}

Keywords: street space, street spatial configuration, urban form, plots

\section{Introduction}

Street space is an important part of urban space. To make guidelines to optimize the configuration of the street space is one of the tasks of urban design. While street space is enclosed by a plurality of buildings along the street, which are the results of the demands of land use and capacity index, and of the common control under the multiple regulations of fire distance, sunshine rights, setbacks and etc. Research on the morphological mechanism of the street spatial configuration is the basis of the urban design.

Studies have shown that the form of street buildings are influenced directly or indirectly by urban regulations, plots and plot index (Talen, 2012; Marshall, 2011). For the European and
American cities, specific to the street interface form, the urban regulations such as density, fire protection, daylighting and ventilation, have a direct effect on the height, position, width and appearance of the street interface (Barnett, 2011; Green,2011; Kropf, 2011; Talen, 2012). And the urban spatial perception of the skyline, surface, architectural style, materials, street surface activities and other regulations on the shape all have different influence on the form (Kostof, 1991; Marshall, 2011; Lehnerer, 2013). Many architects and planners in China realize that physical space is not only a design achievement, but also closely related to the urban system and regulations, such as land ownership and demarcation, the supply mode of public service, and the tax model etc. (Zhao, 2011). Ding(2007) carried out a special 
study on Nanjing, based on the building size, construction distance, building spacing, architectural façade and other aspects, studying the policy on urban form control strategy. But the detailed effect of the existing regulations and indicators system on the street building forms still need to be thoroughly combed. Especially in the theoretical framework of urban morphology, how the regulations play the role on street buildings on the street/block, plot/building scale? And what elements have specific relevance to the configuration in these scales? These questions are worth exploring deeply.

For this reason, the paper tries to study the mechanism on Morpho perspective, that is, to study how indicators, regulations, streets, plots and buildings work together on the street spatial configuration in Chinese context. Three streets of different locations and functions in Nanjing City are selected as the research cases, where the plot size/pattern, the building capacity, and etc. are calculated, the corresponding regulations such as setback laws of different periods and etc. are collected. The correlation between buildings alignments in the plots along the streets with the regulations and the indicators are analyzed. As a conclusion the research finds that the irregularity of the buildings on both sides of the street space is determined by the setback red line regulations of different periods, the discontinuities of the buildings are determined by fire regulations, division of plots, and functions (commercial or residential). Confronting the dynamic disciplines of urban street spatial configuration, urban design is going to be carried out.

\section{Methodology}

In order to deal with these three issues, the method used in the study has two dimensions. Firstly, regarding the plot as a basic unit, the paper sorts out the different age of urban rules and regulations which had direct or indirect effect on street buildings. Then, according to the regulations, the variable models based on the street width, plot layouts and plot index are established. According to the mathematical law of the models, the number $\square$ the façade width and the position of the street buildings are analyzed on their relationship with the street width, plot layouts and plot index. To do this, two groups of material are needed. One is composed of the exact boundary of parcel, the time of plot allocation, the planning land use, red line, limit height, land use index, the built height and so on. The other is composed of urban construction laws and regulations for different periods corresponding to the allocation the plots, such as plan guidelines, planning and management of technical provisions, planning and implementation rules, architectural design norms, fire code and so on. Both groups can be obtained through the Planning Bureau and The Planning archives.

Secondly, considering the statistical method of street buildings and their alignment, it is an operable to analyze the shape characteristics of the street buildings in geometrical and quantitive way. The illustration and quantification technology has accumulated for many years in the world (Krier, 1979; Hillier and Hanson, 1984; Salat, 2011). Because of the difference of the urban space in western cities and in Chinese ones, many scholars define new index to quantify the geometry

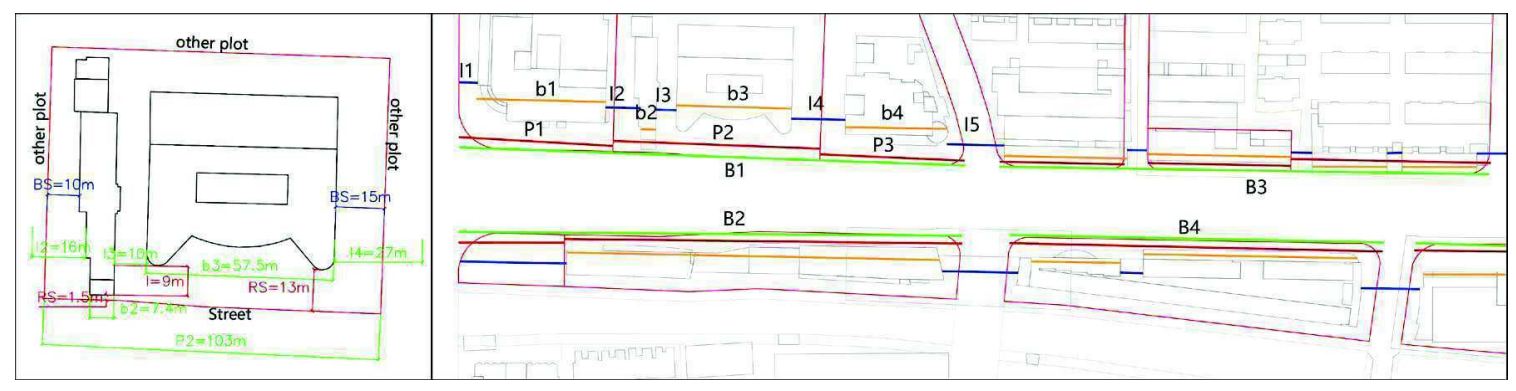

Figure 1.

Measurements of the length of blocks, plots, buildings and building intervals 
of the interface patterns of streets in China. The indexes of integration degree, building correlation and line ratio are put forward and applied (Li, 2007; Qi, 2010). Based on these studies, the paper analyzes the influence of different scales by calculating the ratio of total building length to street, block and plot length, as well as the maximun distance of different setback in blocks and plots. They are regarded as the references in various scale analysis. See figure 1, each length of the block, plot, building and buiding interval are numbered, measured and counted. Based on the measurements, the ratio are calculated.

\section{Research on items of urban rules}

\section{Urban regulations}

\subsection{Street width}

In contemporary city, road is divided into expressway, main road, secondary road and branch. At present, the general red line width of main road in most cities is $35 \sim 60 \mathrm{~m}$, it is regulated that the public building access with high car flow, pedestrian flow should not be set on both sides of the main road. The general red line width of secondary road is $28 \sim 40 \mathrm{~m}$. The branch road mainly serves district, the red line width is 16 28. These regulations on the width have restricted the basic width of street. The regulations in different ages are different a bit.

\subsection{Building setback regulation}

Over year of construction, the buildings on both sides of street in downtown of Nanjing have restricted by laws and regulations in different ages, the main time nodes include 1928, 1978, 1995, 1998, 2004 and 2007.

1) Building setback for road: See the setback regulations in different years in the figure, from 1928 to 2007 , there were 16 setback distances, especially after 1995, building of different heights must have different setback. It can be imagined that even if on the same street, the construction year of building is similar, as long as the building height is different, the setback distance will be different, the street wall will be uneven, and much less the buildings on the same street are completed in different years.

2) Building setback for land boundary: See the regulation on building setback for land boundary in different years in the figure, from 1928 to 2007, there were 9 setback distances. The regulation on setback for land boundary means to the street building that as long as the lands are adjacent, there will be $6 \sim 30 \mathrm{~m}$ distance between buildings, which directly decides the continuity of frontage street.

To combine the regulation on building setback for road and setback for land boundary, laws from 1928 to 2007 regulated 43 building frontage positions (Fig.2). There were 26 possibilities of building position regulated by laws in 2004. Laws are formulated on the basis of code for fire protection, seismic prevention, etc., however, the specific influence on the architectural form of street building is not expected.

\subsection{Building}

Technical Regulation on Urban Planning Management in Jiangsu Province specifies the building base control index, besides regulating the minimum area of building base of residential building and non-residential building of different heights, it also regulates the maximum value of building density and plot ratio. To the building of some type, the plot ratio and building density are restricted. For example, the maximum value of base area of multi-storey residence is $1000 \mathrm{~m} 2$, the building density cannot be more than $28 \%$ in new area, cannot be more than $30 \%$ in the old area, the plot ratio in new area cannot be 1.7 , and cannot be more than 1.8 in the old area.

\subsection{Other}

Besides the regulation on building setback, capacity control, etc., the position of frontage building is also regulated by fire protection, daylighting spacing, etc. For example, according to the regulation of firefighting law, "when the length of frontage building is more than $160 \mathrm{~m}$, no less than $4 \mathrm{~m} * 4 \mathrm{~m}$ fire lane shall be set. The pedestrian exit spacing should not be more than $80 \mathrm{~m}$, when the building length 


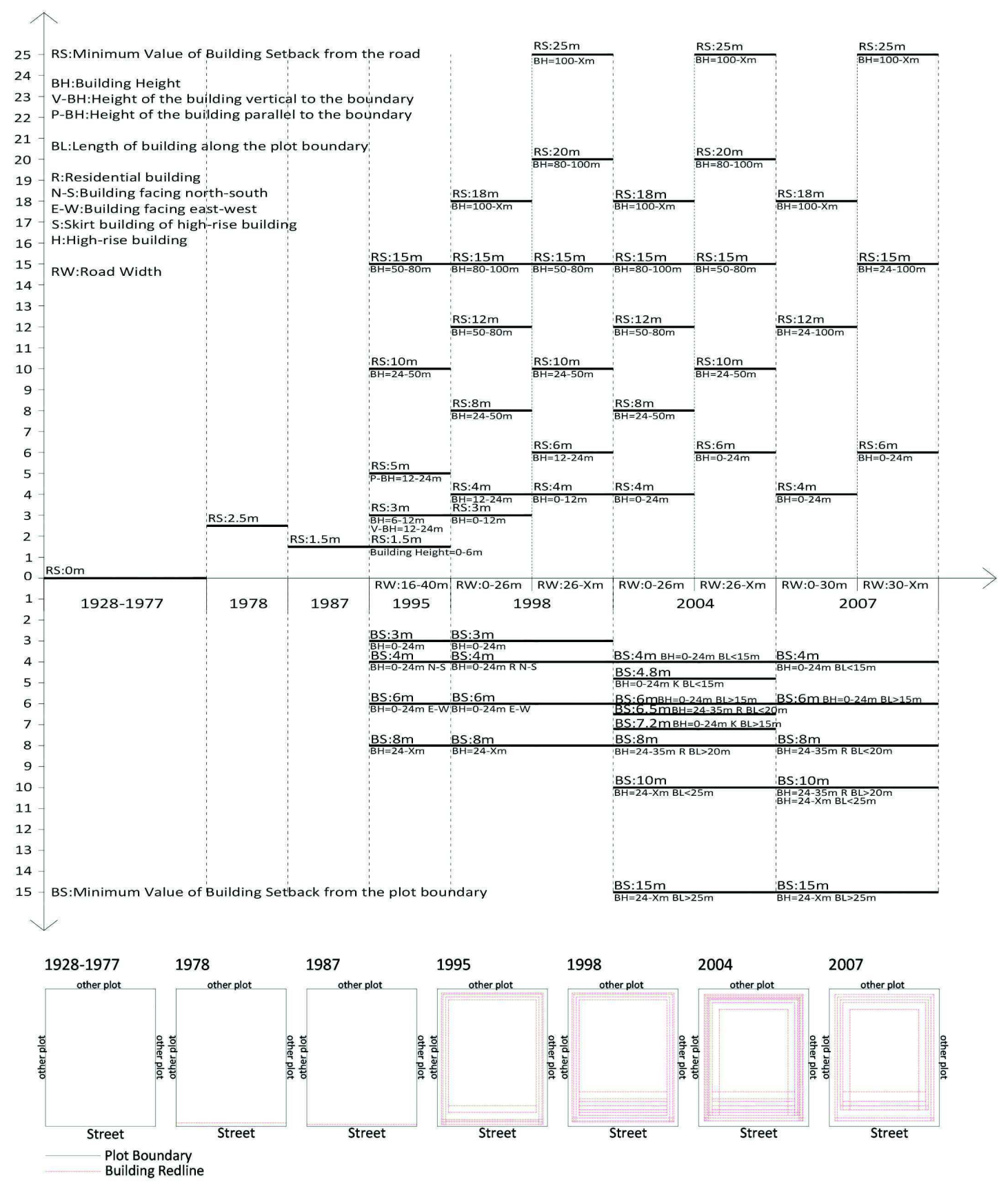

Figure 2.

Summary of setback regulations of successive years

is more than $80 \mathrm{~m}$, pedestrian passage shall be added on the base floor;" the building length is restricted by this regulation. For another example, to residential building, daylighting spacing is especially strict, when the frontage building is residential building, the position setting shall also consider the shielding from the existing building in the south.

When the building position is strictly regulated by the building setback law, the plot ratio and coverage rate are restricted, and the fire protection and daylighting spacing regulation are considered at the same time, the form of street building has been initialized and can be changed within the limit in some interval. What does this interval mean to visual perception? Simulating on the model can have preliminary judgment. 


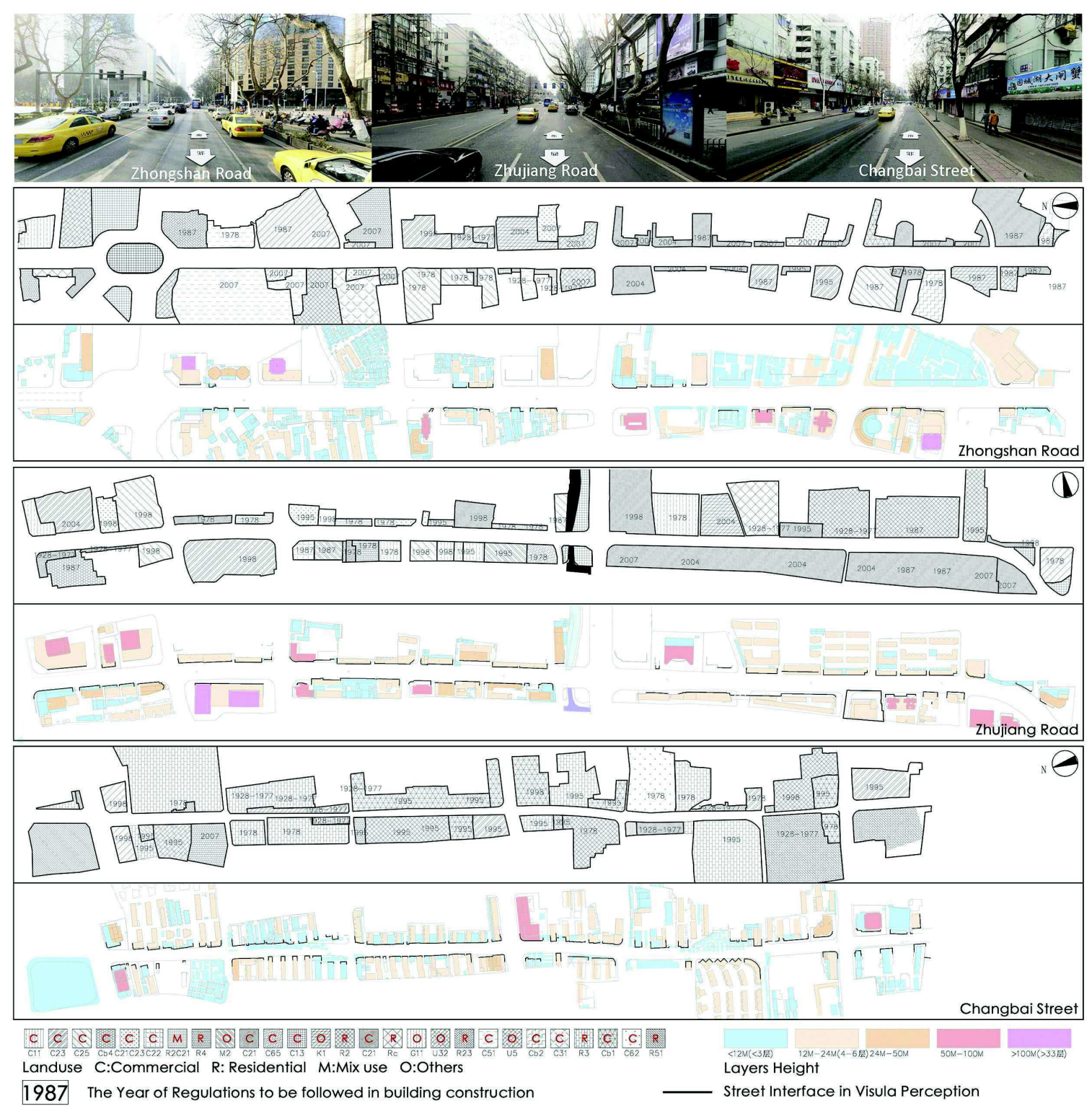

Figure 3.

Basic information of three street cases

Case studies on three streets: Analysis on the causes of layouts of street buildings based on the streetscape ruler

\section{Analysis on the street scale}

Three $2000 \mathrm{~m}$ streets in the old urban area of Nanjing are selected in the research for indepth analysis (Fig. 3). In which Zhongshan Road is the urban main road, the road red line distance is $42-52 \mathrm{~m}$, with commercial land and building on both sides. Zhujiang Road is the secondary urban road in east and west direction, the road red line distance is $35 \mathrm{~m}$, with mixed commerce and residential land on both sides. Changbai Street is south-north living main road, the road red line is $24 \mathrm{~m}$, with residential land and building on both sides. The three street cases correspond with different street widths, different service natures and different orientations respectively.

Later, the researcher makes statistics of block length, land length, land quantity, branch quantity, land nature, building face width, building quantity, building spacing, land plot ratio, coverage rate, building construction year, etc. of the three streets, so as to prepare for analyzing the form composition of frontage 


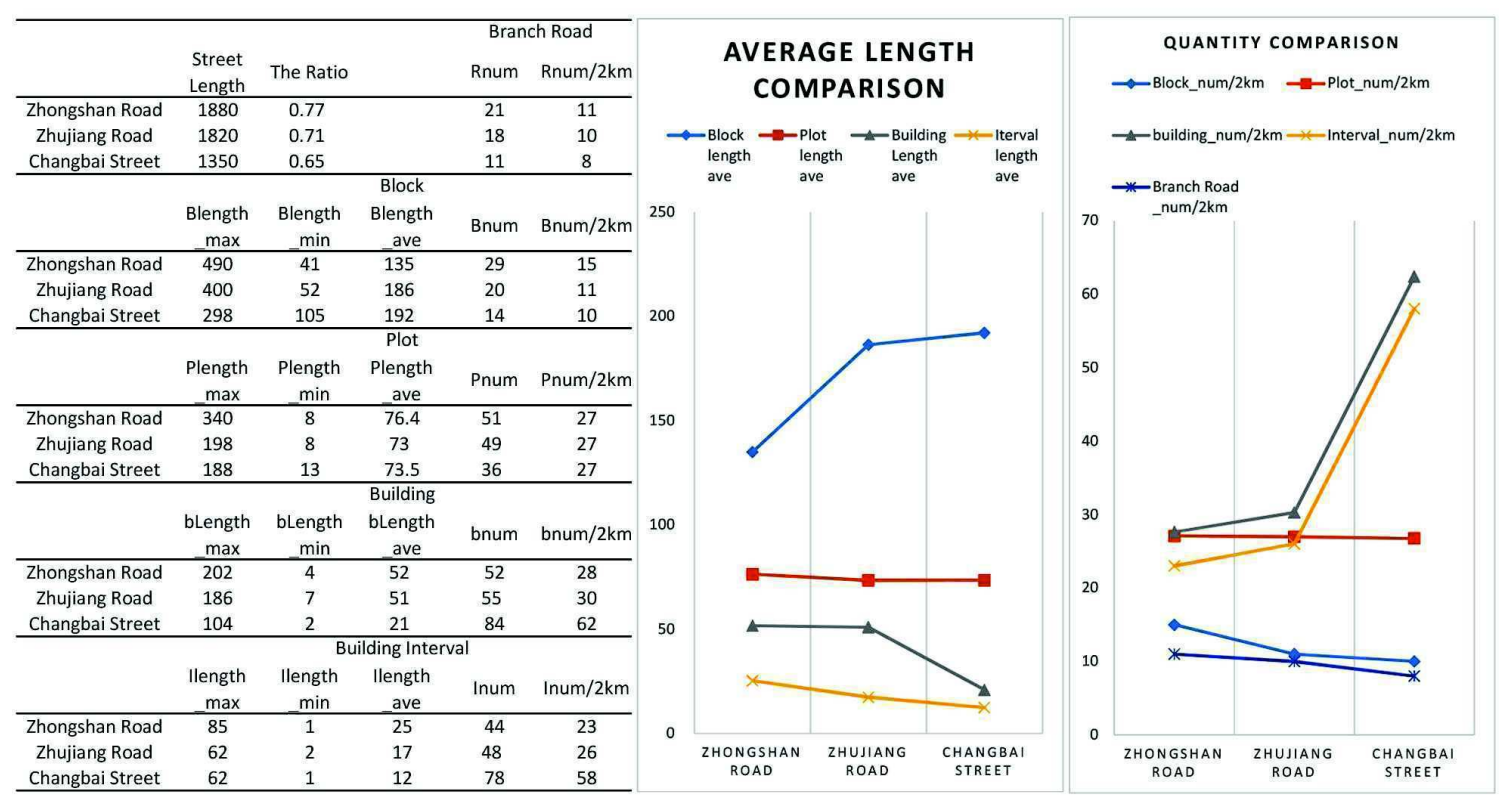

Figure 4.

Basic statistics of three streets

street under the comprehensive function of land, land combination, urban law, land plot ratio, etc. The building data source is the surveying and mapping data of Nanjing Planning Bureau in 1997. The building year is judged according to the image maps in 1949, 1976, 1990, 1998, 2004, 2005-2015.

Statistics show that the quantity of branches of Zhongshan Road, Zhujiang Road and Changbai Street are 11,10 and 8 per $2 \mathrm{~km}$. The result corresponds to the average length of the blocks. The value of the average length of blocks in Zhongshan road is the smallest, followed by Zhujiang Road and Changbai Street. The average length of plots along the street of the three street are approximate, the value is about $75 \mathrm{~m}$. There are large difference in the value of average width and quantity of buildings, especially in Changbai Street, the quantity value is quite high, but the average width value is quite. In terms of the building intervals, the average value of Zhongshan Road is the largest, Zhujiang Road is the smallest. While considering the quantity of the intervals, the result is on the opposite. The values of Changbai Street is twice higher than the one of Zhongshan road and Zhujiang Road. This means there are more buildings in the plots of Changbai Street. The paper then analyses the causes of these statistics in detail.

\section{Analysis on the block scale}

Based on the statistics of the 63 blocks in the three streets, in the block scale, the paper calculates the ratio of building length to the block length (use 'the Ratio' in the following text) and the maximum distance of the setbacks of the street building in the blocks (use 'the Irregularity distance' in the following text), then studies their correlation relationship with the block length, the quantity of the plots and buildings, and so on. The main aspects of the influence on the street space configurations are summarized.

The effect of the length of the blocks: Through correlation analysis (Fig.5), it is found that for three streets, with the length of the block increasing, the Ratio has a different trend. Zhongshan Road and Zhujiang Road are positive correlation, that is, the greater the length of the block, the greater of the ratio, The trend of Zhujiang road is especially obvious. The Changbai Street shows a completely different trend. When the length of the block increases, the Ratio is smaller. Because the Changbai Street is the north-South residential street, the buildings along it are narrow. In order to meet the residential area of the sunshine norms, there is a great distance between buildings, and this point also can be seen from the number of buildings. While both 


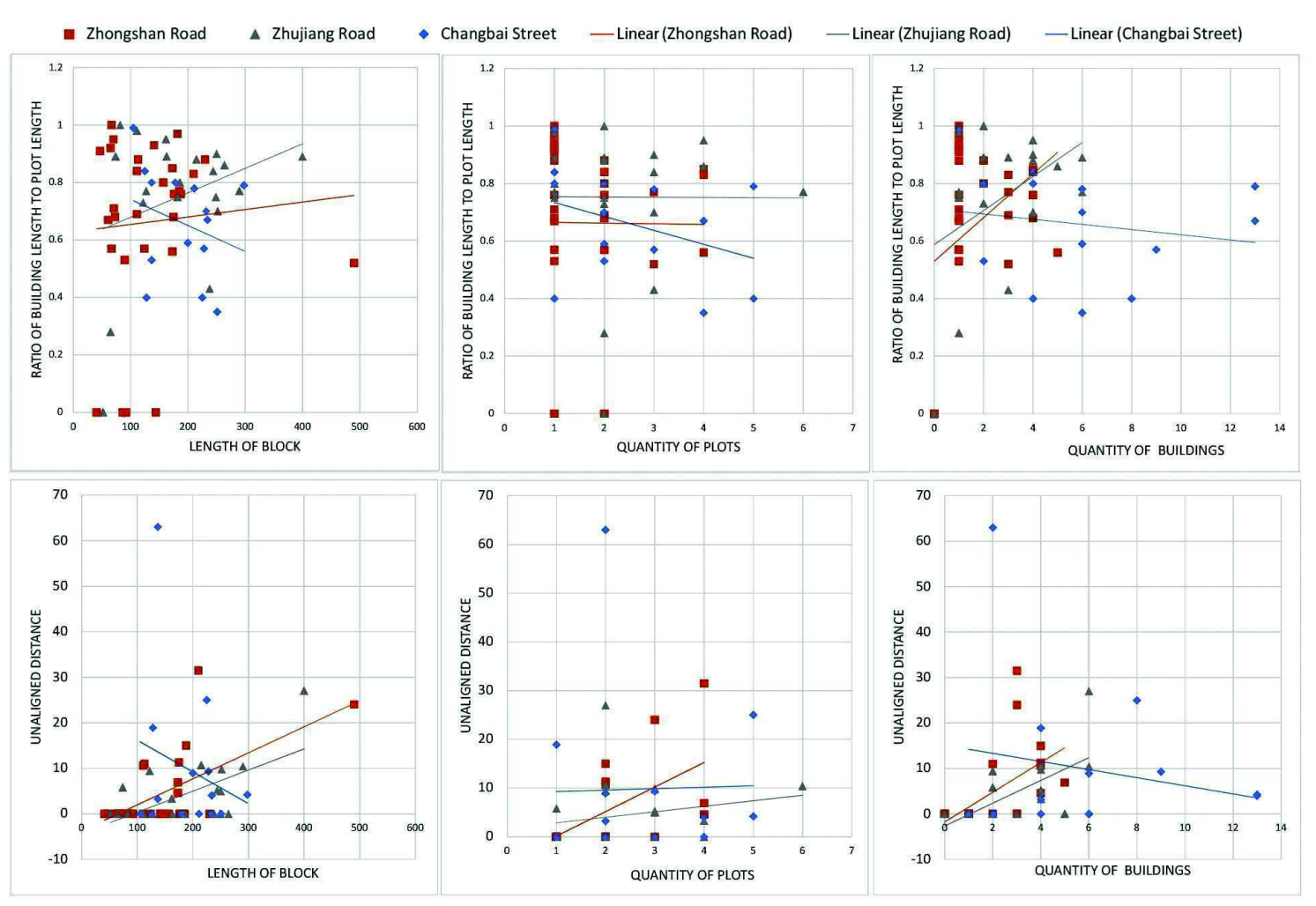

Figure 5.

The correlation analysis between the Ratio and the block length, plots\&building quantity

sides of Zhujiang Road are also residential plots, for it is east-west to the street, there is no demands of sunshine spacing between the buildings. Instead, the longer of the plot, the longer of the building. So the Ratio will be greater. In addition, although Zhongshan Road is a north-south street, but the two sides are mainly commercial-type plots which not affected by the sunshine spacing. On the other hand, for Zhongshan Road and Zhujiang Road, the longer the block length, the more obvious the Irregularity. The situation in the Changbai Street is on the opposite, the longer the block length, the Irregularity is less obvious. In other words, for commercial streets, the longer the block, the longer the length of the Ratio, the greater the Irregularity. For the living streets of the east and west, the regular still exists. But for the north-south to residential streets, in the case of buildings without a skirt building, the longer of the plot, the smaller of the Ratio, the more the Irregularity.

The effect of the quantity of the plots and buildings: The results show that for Zhongshan
Road and Zhujiang Road, the number of plots in the block is not directly related to the Radio. But for the Changbai Street, the more the number of plots, the Radio is smaller. In Changbai Street, There is no direct relationship between the number of plots and the different concessions of buildings. For Zhongshan Road and Zhujiang Road, the larger the number of plots, the more obvious the Irregularity is. And the more of buildings, the larger of the Radio in Zhongshan Road and Zhujiang Road. But it is opposite in Zhongshan Road. The number of buildings has a similar effect on the Irregularity. In other words, the relationship between the number of plots and the Radio is not obvious. For the north-south residential area, the more plots, the smaller the proportion of buildings. For commercial streets, the more plots in the block, the more likely the building will be different concessions. The larger the number of buildings, the greater the Radio, the greater the likelihood of a building yielding different concessions, except for the north-South Living Street. 


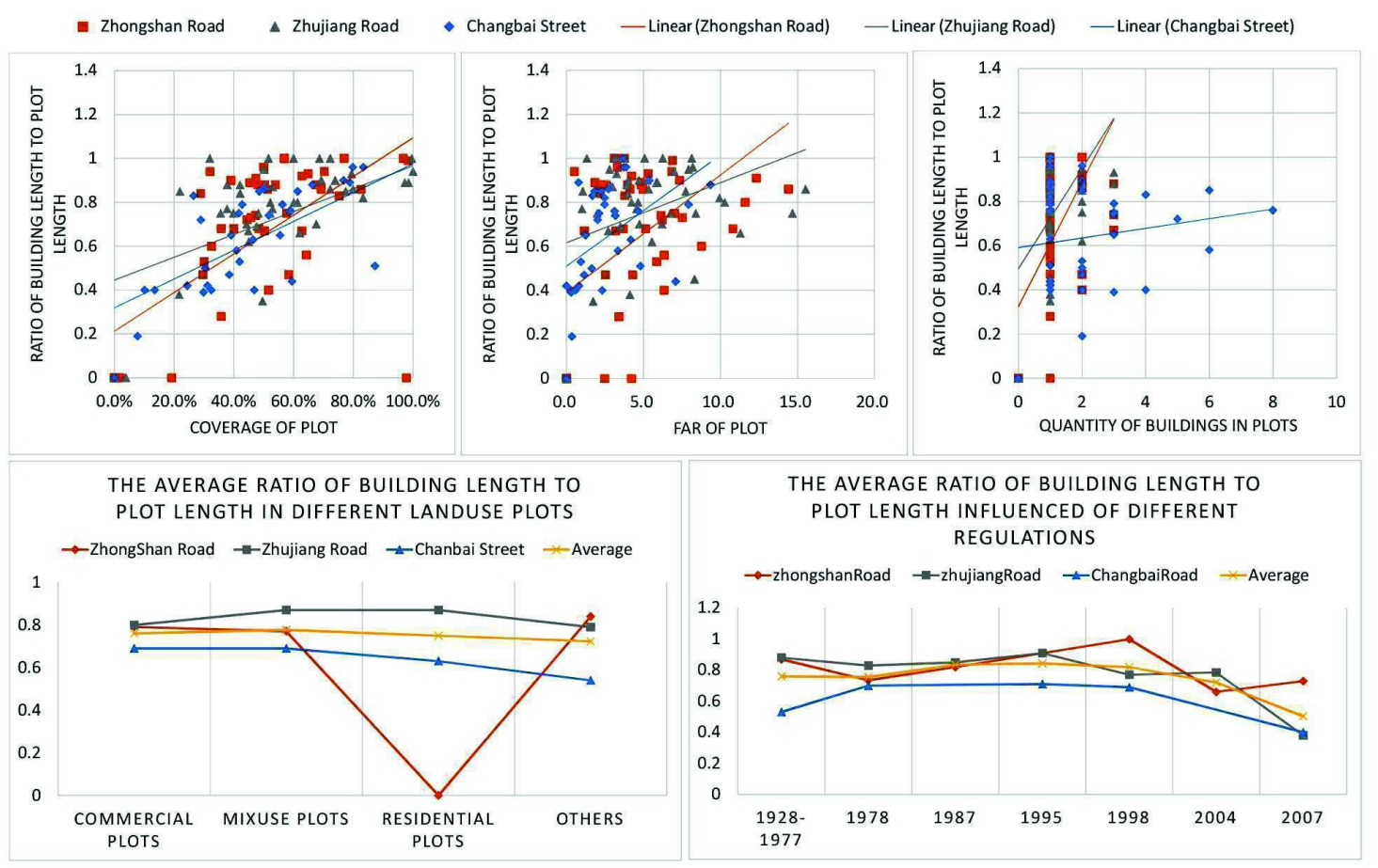

Figure 6.

The correlation analysis between the ratio and the plot FAR, coverage, and etc

\section{Analysis on the plot scale}

The study then focuses on the ratio of the building length to the plot length (use 'the ratio' in the following texts), and its correlation relationship to the coverage, FAR of the plots, quantity of the buildings, and land use. Based on the statistics of 136 plots in the three streets, the factors related to the spatial configuration of the street space are analyzed.

The effect of the Plot Coverage and FAR: The study finds that the ratio is positive correlation with the FAR and coverage of the plots. That is, the higher the coverage and FAR, the higher the ratio. The statistic of Zhongshan Road and Zhujiang Road shows that there are not many buildings in the general plot (1-3). The more the building, the higher the ratio. The quantity in Changbai Street is much more till 8. Thus, the quantity is not much correlated with the ratio.

The effect of the land use of the plots: The statistics of the ratio of different land use show that for the Zhujiang Road, the value of residential and commercial mixed plot is larger than that of commercial one. Zhongshan Road has no residential plot, the value of commercial plot is comparable to that of Zhujiang Road. The value of Changbai Street is lower than that of other streets, and the ratio of residential plots is lower than that of commercial and mixed ones. As a result, the ratio of east-west street is higher than the north-south street.

The effect of different years of regulations: According to the statistics of different yeas of buildings construction, since 2004, the value of the ratio is become lower. The value of the ratio in 1978, 1987 and 1995 is relatively high. Corresponding to Fig. 2, with the gradual increase of the height of the buildings and the refinement of the regulations of setback and intervals, the street space configuration have changed greatly.

\section{Conclusion}

The paper studies and collates the laws and regulations which have an important influence on the Nanjing Street Configuration, and makes a detailed analysis in the street, block and plot scale, and obtains the following conclusions: 
1. The construction laws and regulations and the changing of them have shaped the composition of the street space. The influence exists especially in the setback and intervals of buildings. In the case of Nanjing regulations, the regulations in 2004 and later has led to the separation of the street buildings.

2. Under the control of specific regulations, it is the length of the block and the quantity of the street buildings in the block, not the quantity of plots, that will affect the ratio of the length of the buildings to the length of the block, and in general, the higher the ratio, the greater the Ratio. While considering the Northsouth residential street, the opposite is true.

3. The ratio of buildings length to the plot length is positively correlated with the length, FAR and coverage of the plots. That is, the larger their value, the large the ratio. The ratio is also related to the land-use, the ratio of the residential plots along the east-west street is higher than that of the commercial plots.

Therefore, before the urban designer intervenes, the street space configuration is the results of city regulations under the conditions of typical blocks and plots. Good urban street space configuration is not only the results of good urban design, but also the results of niche targeting urban rules considering the different conditions of street, block and plot. Under the condition of modern city's high density, the good street space can still exist with the modern operation mode; the good form controlling should include the future-oriented method which synthesizes more factors.

\section{Acknowledgement}

This study was financially supported by National Natural Science Foundation of China (No.51538005) and China Postdoctoral Science Foundation (No. 2016M591823).

\section{References}

Barnett, J. (2011). How Codes Shaped Development in the United States, and Why They Should Be Changed. Marshall, S. (Ed.). Urban coding and planning. Routledge.
Ding, W. (2007). Study on urban morphology and its shaping control in Nanjing. Nanjing University.

Green, N. (2011). A chronicle of urban codes in pre-industrial London's streets and squares. Urban Coding and Planning. New York: Routledge.

Hillier, B., Hanson, J., \& Peponis, J. (1984). What do we mean by building function?. E \& FN Spon Ltd.

Kostof, S. (1991). The city shaped: Urban patterns and meanings through history. Thames and Hudson.

Krier, R., \& Rowe, C. (1979). Urban space. London: Academy editions.

Kropf, K. (2011). Coding in the French planning system: From building line to morphological zoning. Urban Coding and Planning. London: Routledge, 158-249.

Lehnerer, A. (2009). Grand city rules. 010 Publishers.

Li, Y. (2007). The research of the Block Integrity Degree Controlling Factor. Nanjing University.

Marshall, S. (Ed.). (2012). Urban coding and planning. Routledge.

Qi, Z. (2010). Study of parallel ratio as a controlling factor of block's complete ratio. Nanjing University.

Salat, S., Labbé, F., \& Nowacki, C. (2011). Cities and forms: on sustainable urbanism. Paris, France: Hermann.

Talen, E. (2012). City rules: How regulations affect urban form. Island Press.

Zhao Y.(2011) The Institutional Genes of Urban Landscape. Time+Architecture, 3:1013. 